\title{
Significance of complete right bundle-branch block with right axis deviation in absence of right ventricular hypertrophy
}

\author{
Agustin Castellanos, Jr., Orlando Maytin, Azucena G. Arcebal, ${ }^{2}$ and Louis Lemberg
}

From the Section of Cardiology, Department of Medicine, University of Miami

School of Medicine, and the Division of Electrophysiology, fackson Memorial Hospital

and Veterans Administration Hospital, Miami, Florida, U.S.A.

Complete right bundle-branch block with right axis deviation was seen in nine patients who did not have right ventricular hypertrophy, pulmonary disease, or extensive lateral myocardial infarction. Four patients had chronic block and five had acute myocardial infarction. This pattern was attributed to a coexisting block in the right branch and in the inferior division of the left branch. It frequently alternated with other significant intraventricular conduction defects, namely, complete left bundle-branch block, complete right bundle-branch block, and complete right bundle-branch block with block in the superior division of the left branch. A type II Mobitz block, evolving from a prolonged, or normal, $P R$ interval, appeared in eight patients. The latter was probably due to a simultaneous conduction disturbance in the right branch and in both divisions of the left branch (trifascicular block). All patients required intracardiac pacing. The prognosis was not good due to the extensive involvement of the conducting system.

'But there is another way in which the electrocardiogram may suffer change in form, namely, by variations in conduction along the bundle branches and their divisions.'

Sir Thomas Lewis. The Mechanism and Graphic Registration of the Heart Beat. 1920

The electrophysiological mechanisms and clinical significance of complete right bundlebranch block with right axis deviation have aroused considerable interest. Several terms have been applied to this conduction disturbance: classical (Grishman and Scherlis, 1952; Holzmann, 1953), uncommon (Katz, I946), and rare (Evans and Turnbull, 1937; Jouve, Senez, and Pierron, 1954; Taimont et al., 1952; Toyoshima et al., 1956; Vastesaeger, I946). Rosenbaum, Elizari, and Lazzari (1967) have stressed a most intriguing aspect of this type of block. They observed that though frequently associated with right ventricular

Received 17 April 1969.

1 Supported by Grants from the Florida Heart Association, The Heart Association of Greater Miami, and the Developmental Fund.

2 Research Fellow of the Florida Heart Association. hypertrophy and pulmonary disease, it could also occur in patients with left ventricular hypertrophy. Knowledge about the natural history of acute and chronic heart block, by means of conventional and continuous electrocardiographic monitoring, has shown that complete right bundle-branch block with right axis deviation is frequently associated with other, more severe, symptomatic intraventricular and atrioventricular conduction defects (Rosenbaum, I968; Castellanos et al., I969).

The purpose of this report is to present important information regarding the genesis and significance of this anomaly in the absence of right ventricular hypertrophy.

\section{Case Material}

Electrocardiographic information obtained from 9 patients having complete right bundle-branch block with right axis deviation is presented in the Table. The tracings were collected in a 7-month period, but since not all electrocardiograms obtained in our institution were interpreted by the authors, it is possible that other examples of this conduction disturbance might have been missed. The AQRS was located between $+95^{\circ}$ and $+140^{\circ}$. In lead I, the size of the $S$ wave was equal to, or 
TABLE Data of patients with complete right bundle-branch block and right axis deviation

\begin{tabular}{|c|c|c|c|c|c|c|c|}
\hline $\begin{array}{l}\text { Case } \\
\text { No. }\end{array}$ & Age (yr.) & $A Q R S$ & $\begin{array}{l}\text { Longest } P R \text { interval } \\
\text { during } I: I \text { conduc- } \\
\text { tion }(\sec .)\end{array}$ & $\begin{array}{l}\text { Type of } A V \\
\text { block }\end{array}$ & $\begin{array}{l}\text { Other conduction } \\
\text { disturbances }\end{array}$ & $\begin{array}{l}\text { Location of } \\
\text { myocardial } \\
\text { infarction }\end{array}$ & Outcome \\
\hline
\end{tabular}

\section{Chronic block}

\begin{tabular}{|c|c|c|c|c|c|c|c|}
\hline $\begin{array}{l}1 \\
2 \\
3 \\
4\end{array}$ & $\begin{array}{l}34 \\
62 \\
44 \\
5 I\end{array}$ & $\begin{array}{l}+120^{\circ} \\
+130^{\circ} \\
+115^{\circ} \\
+125^{\circ}\end{array}$ & $\begin{array}{l}0.23 \\
- \\
0.28 \\
0.25\end{array}$ & $\begin{array}{l}\text { Mobitz II } \\
2: \text { I } \\
\text { Mobitz II } \\
\text { Mobitz II }\end{array}$ & $\begin{array}{l}- \\
\text { CLBBB-ILBBB } \\
\text { CRBBB + BSDLB } \\
-\end{array}$ & - & $\begin{array}{l}\text { Asymptomatic } \\
\text { Dead } \\
\text { Pacer } \\
\text { Pacer }\end{array}$ \\
\hline \multicolumn{8}{|c|}{ Acute myocardial infarction } \\
\hline 5 & 53 & $+110^{\circ}$ & 0.22 & Mobitz II & $\begin{array}{l}\text { CRBBB, } \\
\text { CRBBB + BSDLB }\end{array}$ & Antero-septal & Dead \\
\hline 6 & 39 & $+120^{\circ}$ & 0.23 & Mobitz II & $\begin{array}{l}\text { BSDLB, } \\
\text { CRBBB + BSDLB, } \\
\text { CLBBB }\end{array}$ & Antero-septal & Dead \\
\hline 7 & 58 & $+125^{\circ}$ & $0 \cdot 16$ & Mobitz II & $\begin{array}{l}\text { BSDLB, } \\
\text { CRBBB + BSDLB }\end{array}$ & $\begin{array}{l}\text { Antero-septal } \\
\text { + high-lateral }\end{array}$ & Dead \\
\hline 8 & 73 & $+140^{\circ}$ & 0.23 & Mobitz II & - & Inferior & Alive (I mth.) \\
\hline 9 & 70 & $+115^{\circ}$ & 0.16 & Mobitz II & CRBBB + BSDLB & Anterior & Alive_(I mth.) \\
\hline
\end{tabular}

$\mathrm{CRBBB}=$ Complete right bundle-branch block. $\mathrm{CLBBB}=$ Complete left bundle-branch block; ILBBB, incomplete to left bundle-branch block; BSDLB, block in the antero-superior division of the left branch.

larger than, the $\mathbf{r}$ wave. Right ventricular hypertrophy and pulmonary disease were excluded by clinical, radiological, and laboratory data. Left ventricular hypertrophy was detected by $x$-ray five times. Four patients had chronic block diagnosed by historical, angiographic, and post-mortem absence of coronary artery disease. There was one sudden death in this group. The remaining 5 patients had well-documented evidence of acute myocardial infarction. Of these, two were anteroseptal, one strictly anterior, one inferior, and one antero-septal with high lateral involvement (changes in aVL, but not in $\mathrm{V}_{5}$ and V6). Other types of intraventricular conduction defects were present in 6 of the 9 patients, namely, complete left bundle-branch block; incomplete left bundlebranch block; block in the superior division of the left branch; isolated complete right bundle-branch block; and complete right bundle-branch block with block in the superior division of the left branch. The onset of type II Mobitz block was observed in 8 cases. All but two patients had a prolonged PR interval (greater than $0.2 \mathrm{sec}$.) during periods of $I: I A V$ conduction.

Block in the superior division of the left branch was diagnosed according to the criteria of Rosenbaum et al. (1967) and Pryor and Blount (1966): (a) abnormal left axis deviation (between $-30^{\circ}$ and $-90^{\circ}$ ); (b) small $\mathrm{r}$ waves in leads II, III, and aVF; (c) counterclockwise rotation of the frontal plane QRS loop; (d) exclusion of other causes of abnormal left axis deviation, namely, inferior infarction, pulmonary emphysema, right ventricular apical pacing, hyperkalaemia, and Wolff-Parkinson-White syndrome. The diagnosis of block in the inferior division of the left branch required
(Rosenbaum et al., 1967; Castellanos et al., I969; Pryor and Blount, 1966): (a) AQRS between $+90^{\circ}$ and $+130^{\circ}$; (b) small q waves in leads II, III, and aVF ; (c) clockwise rotation of the frontal plane QRS loop; (d) exclusion of other causes of right axis deviation, namely, right ventricular

FIG. I Case I. Complete right bundle-branch block with right axis deviation due to block in the inferior division of the left branch. There is first degree $A V$ block in the upper strips and a type II Mobitz block in the lower tracing.

Blockage of $P$ waves was attributed to a simultaneous coexisting conduction disturbance in the right branch and in both divisions of the left branch (trifascicular block).

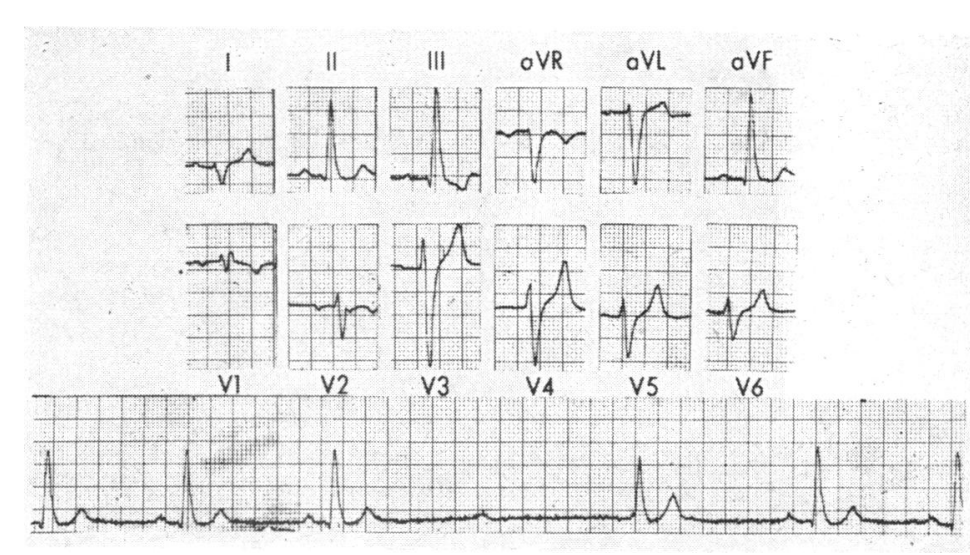




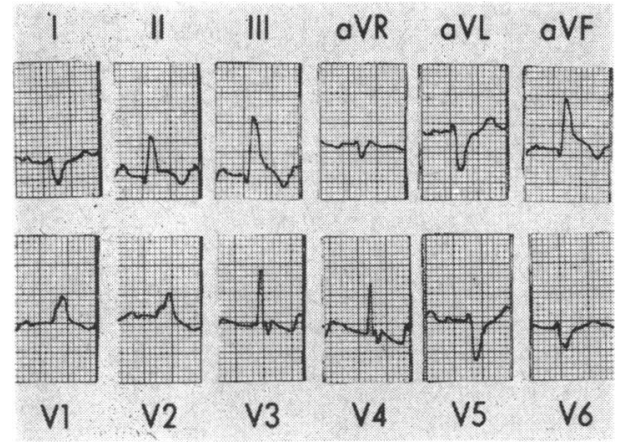

FIG. 2 Case 8. Complete right bundle-branch block with block in the inferior division of the left branch and first degree $A V$ block in a patient with acute inferior wall infarction.

hypertrophy, pulmonary disease, extensive lateral infarction, or extremely vertical hearts. It is important to emphasize that both block in the superior division of the left branch and in the inferior division of the left branch can be diagnosed in the presence of complete right bundlebranch block.

A type II Mobitz block implies that blocked P waves should not be preceded by progressive PR prolongation (Mobitz, 1924; Langendorf and Pick, I968). A type II Mobitz block can evolve from a normal or a prolonged PR interval. A fixed type of second degree AV block (for instance, $2: \mathrm{I}$ ) should not be described as type II, since the former can also be the end result of a Wenckebach phenomenon (Langendorf and Pick, I968).

\section{Results}

Examples of complete right bundle-branch block with right axis deviation during chronic block and acute myocardial infarction are presented in Fig. I-7. This and all figures are described in the respective legends. The tracings in Fig. I and 3 show a type II Mobitz block. Fig. 3 is unusual in that this type of block appeared during an inferior, rather than in an anterior, wall infarction. A possible explanation is presented in the discussion. In all patients sudden blockage of the $P$ wave was attributed to a simultaneous interruption of conduction in the three main intraventricular tracts, i.e. in the right branch and in both divisions of the left branch (trifascicular blocks) (Rosenbaum et al., I967). Fig. 4-7 show the various types of intraventricular conduction defects which preceded the development of AV block. Fig. 4 is the control tracing with a normal axis. Pure block in the superior division of the left branch appears in Fig. 5. Cirsplete right bundle-branch block with block in the superior division of the left branch

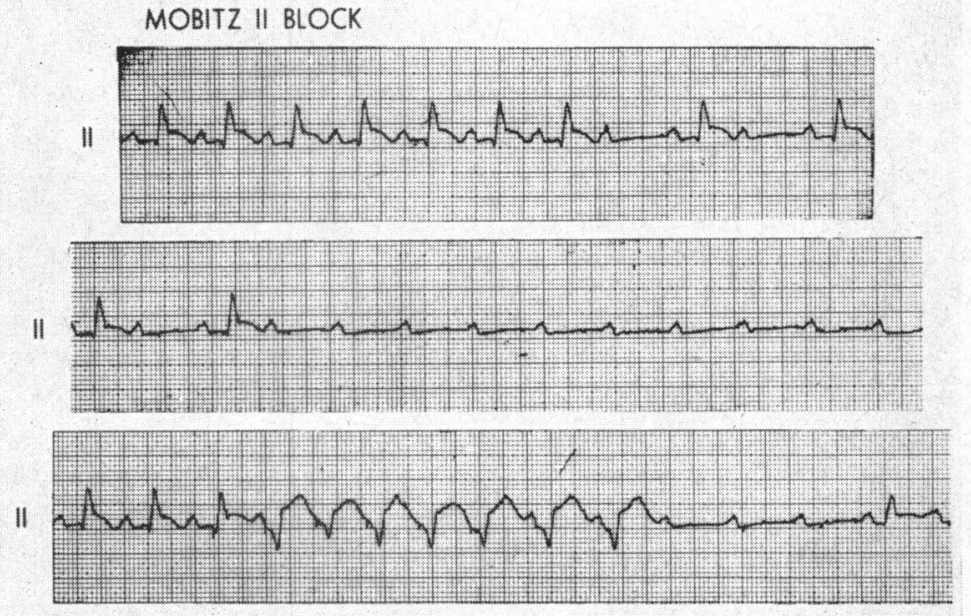

MOBITZ || BLOCK EXPOSED BY VENTRICULAR PACING

FIG. 3 Case 8. The spontaneous onset of type II Mobitz block is shown in the top two strips. In the bottom tracing the block was produced by the concealed retrograde conduction of the pacemaker-induced ectopic ventricular beats.

is shown in Fig. 6. Finally, in Fig. 7, there is complete right bundle-branch block with block in the inferior division of the left branch preceding the appearance of a type II Mobitz block. The latter developed directly from a normal $P R$ interval.

Temporary pacing had to be instituted in all patients (Table). Two of the four patients with chronic block had pacemakers implanted, one died suddenly, and the other one refused permanent electrical therapy. Only two of the patients with acute myocardial infarction left the hospital alive.

FIG. 4 Case 7. Acute anterior wall infarction with a normal electrical axis.

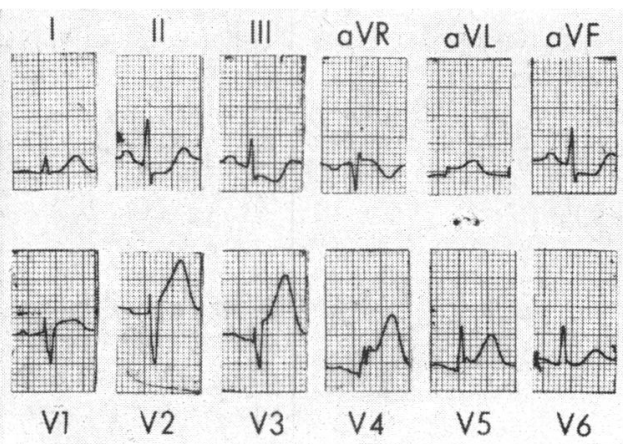




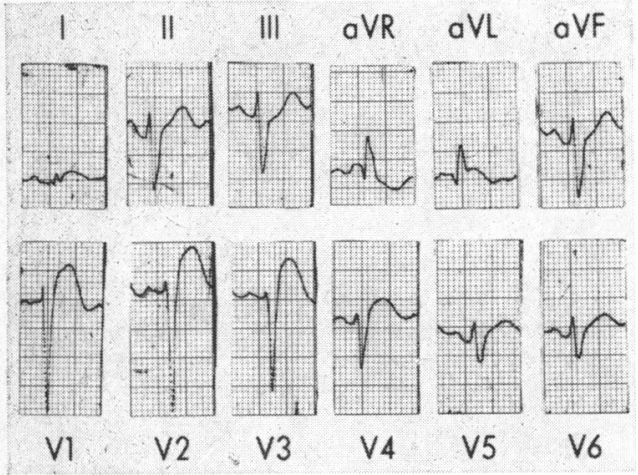

FIG. 5 Case 7. Same patient as in Fig. 4, one day later. The tracing now shows abnormal left axis deviation due to block in the superior division of the left branch.

\section{Discussion}

Significance of complete right bundlebranch block with right axis deviation Several authors have reported that bundlebranch block with abnormal left axis deviation precedes the development of symptomatic AV block (Rosenbaum et al., 1967; Lasser, Haft, and Friedberg, 1968). They have attributed the abnormal left axis deviation to a block in the superior division of the left branch. Hence, this pattern has been interpreted as a form of bilateral bundle-branch block. However, less emphasis has been placed on the fact that complete right bundlebranch block with right axis deviation can also be a precursor of symptomatic AV conduction disturbances (Rosenbaum et al., 1967; Rosenbaum, 1968; Castellanos et al., 1969).

FIG. 6 Case 7. Same patient as in Fig 5, 20 hours later. Complete right bundle-branch block has now appeared. Block in the superior division of the left branch persists. The infarction has evolved.

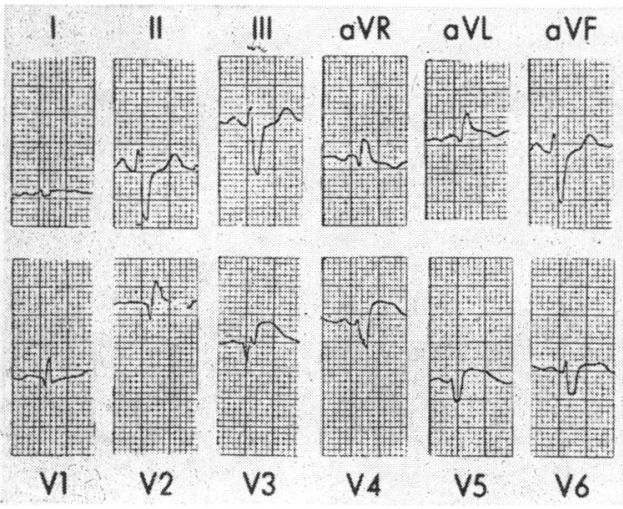

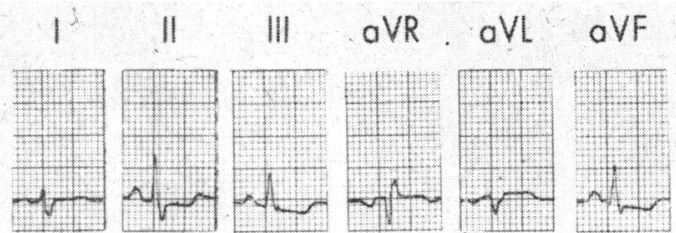
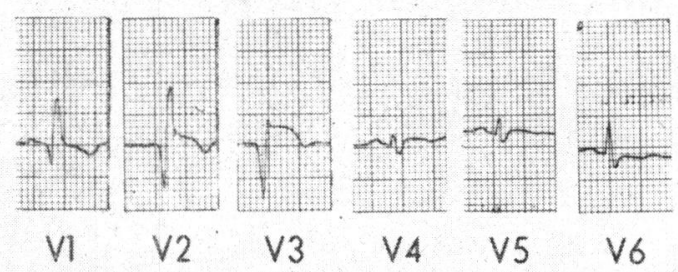

V2

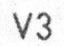

V4

V5

V6

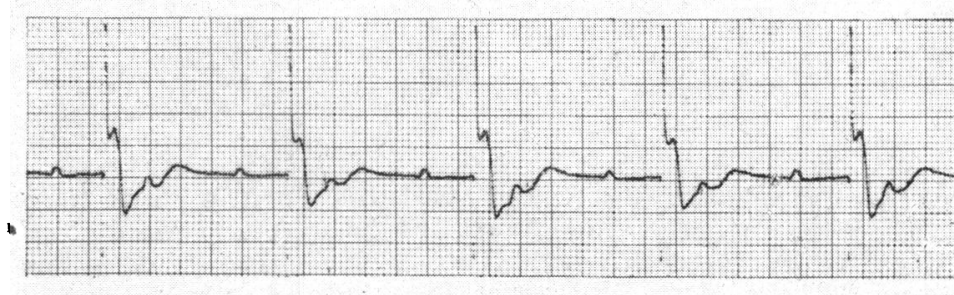

LEAD ॥

FIG. 7 Case 7. Complete right bundle-branch block with block in inferior division of the left branch preceding the onset of $A V$ block requiring intracardiac pacing (lower strip). The $A V$ block was attributed to a simultaneous interruption of conduction through the right branch and both divisions of the left branch (trifascicular block).

Of course, it is well recognized that complete right bundle-branch block with right axis deviation frequently occurs in patients with right ventricular hypertrophy, pulmonary disease, extensive lateral wall myocardial infarctions, and extremely vertical hearts (Rosenbaum et al., 1967). Several authors have stressed that the association of complete right bundle-branch block and right axis deviation, in the absence of the complicating factors mentioned above, represents a simultaneous conduction block in the right branch and in the inferior division of the left branch (Rosenbaum et al., 1967; Castellanos et al., 1969; Kobayashi, 1962; Lepeschkin, 1964). This diagnosis is strengthened by the appearance of advanced AV block.

Diagnosis of pure block in inferior division of left branch The criteria for diagnosis of isolated block in the inferior division of the left branch were established by Rosenbaum et al. (1967) and by Pryor and Blount (I966). 
According to Rosenbaum et al. (1967), when this block exists the electrical impulse proceeds unopposed through the intact superior division. In consequence, the first part of the ventricles to be activated is the superior aspect of the antero-septal regions of the left septum and free left ventricular wall. The initial vectors will thus point superiorly, anteriorly, and to the left. Though a $\mathrm{q}$ wave will not be recorded in leads $\mathrm{I}$, aVL, or high left chest leads, it will be present in II, III, and aVF. This concept of septal activation implies that the initial $Q R S$ vectors are a function of the divisions of the left branch and not of the trunk itself. It conflicts with that of Sodi-Pallares and Calder (1956) who invariably linked the initial vectors to an impulse emerging from the left 'bundle' branch. Rosenbaum et al. (1967) and Pryor and Blount (1966) postulated that both early and mid-terminal activation was a function of the divisions of the left branch and not of the left bundle itself. This theory has been corroborated by recent studies dealing with aberrant conduction of atrial premature beats. Rosenbaum et al. (1967) and Cohen et al. (I968) have conclusively shown that aberration of the block in the superior or inferior left branches changes the orientation of the initial vectors.

In block in the inferior division of the left branch, the middle and terminal forces point inferiorly, posteriorly, and slightly to the right, since activation will proceed in that direction throughout the left ventricle after inscription of the initial vectors. Free left ventricular wall forces are pulled to the right by those produced by the simultaneous depolarization of the septum. Finally, there is a late activation of the postero-inferior regions of the left ventricular wall and septum which was the area normally activated by the blocked inferior division. In consequence, leads II, III, and aVF will show a predominant positive deflection ( $R$ wave). The frontal plane $Q R S$ loop shows the following characteristics in block in the inferior division of the left branch: (a) superior, leftward, and anterior orientation of the initial $(0.02 \mathrm{sec}$.) vectors, (b) clockwise rotation, (c) terminal forces to the right but not necessarily anteriorly, (d) inferior and rightwards deviation of the maximal vector. However, since similar electrocardiograms are found in patients with right ventricular hypertrophy, pulmonary emphysema, or embolism, and extremely vertical hearts, it becomes evident that the diagnosis of block in the inferior division cannot always be made from the electrocardiogram alone (Rosenbaum et al., 1967; Rosenbaum, 1968). Additional clinical, radiological, and pathological information might be required for this purpose.

Association of block in inferior division of left branch and complete right bundle-branch block Dodge and Grant (1956) studied a large number of patients with complete right block in which pre-blocked tracings were available. They noticed that the uncomplicated form usually showed a normal axis. Moreover, the appearance of right block did not produce a significant change in the AQRS. The patients with abnormal left axis deviation (due to block in the superior division of the left branch) in the control tracings showed the same axis after the appearance of complete right block. Hence, both conduction disturbances could be diagnosed in a single electrocardiogram even if pre-block recordings were not available.

Tracings of patients with right axis deviation due to block in the inferior division of the left branch can be seen in the articles by Rosenbaum et al. (1967) and Cohen et al. (1968). This diagnosis could still be made after the appearance of complete right block, thus proving that (in the absence of the complicating factors mentioned previously) the presence of right axis deviation during complete right block represented the association of the latter with a block in the inferior division of the left branch. The presence of a double conduction disturbance is strongly suggested by the coexistence of a prolonged PR interval and by the sudden onset of a type II block. In fact, the PR interval was prolonged in 16 of 21 patients having complete right bundle-branch block with a block in the inferior division of the left branch (Rosenbaum et al., 1967). It has been emphasized that in the presence of a simultaneous block in the right branch and in the inferior division of the left branch an AV block most probably indicates that there is an impedance to conduction (incomplete block) through the superior division of the left branch (Rosenbaum et al., 1967; Rosenbaum, 1968). If conduction is totally interrupted in the latter, the resulting picture is that of 'complete' AV block. It should be stressed that such a block would be 'trifascicular', because it results from the coexistent impairment of conduction in the three main intraventricular tracts, below the bifurcation of the His bundle. Of course, the existence of another area of block, situated above the bifurcation, cannot be definitely excluded (Pick and Langendorf, 1968).

The Table shows that two of the cases of complete right bundle-branch block and block in the inferior division of the left branch 
had a normal PR interval. Yet they developed a Mobitz type II block. It stresses the predisposition of this combination of anomalies for AV block even in the presence of a normal PR interval. A retrospective study by Lasser et al. (1968) seemed to indicate that, when chronic symptomatic AV block was present, the pattern of complete right block with block in the superior division of the left branch was the most frequent associated conduction disturbance. The findings were different from a prospective point of view since only about Io per cent of the patients showing the pattern later developed complete AV block. In contrast, Rosenbaum (1968) noted that close to two-thirds of the patients with chronic block having complete right block with block in the inferior division of the left branch progressed into advanced AV block. In other words, the probabilities were greater for the patient having this latter combination to become symptomatic than for the one having the former combination of anomalies. The data in this communication seem to support this observation though ours was not a prospective study. The four patients with chronic block presented in the Table with no history of angina pectoris or myocardial infarction had normal coronary arteries, by selective angiography and (in one case) by necropsy. Hence, it is probable that they did not have arteriosclerotic heart disease. Rosenbaum et al. (1967) believe that patients with similar characteristics have 'bilateral bundle branch fibrosis', a specific type of heart disease affecting only the corresponding anatomical structures and not the ordinary myocardium (Lenègre and Moreau, I963; Harris, 1968). Rosenbaum et al. (1967) were able to prove the existence of arteriosclerotic heart disease in only 4 of their 21 cases of complete right block with block in the inferior division of the left branch. Their study was performed before the era of intensive coronary care in patients who did not have acute myocardial infarction. Eight had chronic Chagas cardiomyopathy which is frequent in the country from which this study originated. On the other hand, 6I per cent of the chronic block cases with complete right block with block in the superior division of the left branch had arteriosclerotic heart disease (Lasser et al., 1968). These differences can be explained by assuming that block in the superior division of the left branch, isolated, or combined with complete right block, might be produced by relatively small lesions in the antero-septal wall or branching portion of the His bundle (Rosenbaum et al., 1967). On the contrary, the existence of complete right block with block in the inferior division of the left branch presupposes significant septal and bundlebranch lesion due to a massive anterior wall infarction (Rosenbaum et al., I967; Lenègre and Moreau, 1963). Hence, it is easier for a patient with arteriosclerotic heart disease to survive if he has complete right block with block in the superior division of left branch than if he displays the pattern of right block and block in the inferior division of left branch (Rosenbaum, 1968).

Bundle-branch block seems to be more frequent in anterior rather than inferior myocardial infarction (Rosenbaum et al., 1967). This occurs because the anterior descending branch of the left coronary artery contributes significantly to the blood supply of the bundlebranches and superior division of the left bundle (Bosco, 1936; Laubry and Soulié, 1950; Mahaim, I93I; Mahaim, Hatt, and Rivier, 1954). Bundle-branch block occurs in inferior infarction if the latter is associated with significant left coronary disease (Rosenbaum et al., 1967). The blood supply of the inferior division of the left branch depends on the posterior descending artery (Bosco, 1936; Laubry and Soulié, I950; Mahaim, I931; Mahaim et al., 1954), though Rosenbaum et al. (1967) believe that it is related to both anterior and posterior arteries. Block in the inferior division of the left branch can occur as an isolated conduction disturbance in noncomplicated inferior wall infarction (Castellanos et al., 1969). But as mentioned before, when block in the inferior division of the left branch appears in anterior wall infarction, the latter is extensive, and usually coexists with lesions of the other two main intraventricular tracts.

Significance of type II Mobitz block Pathological studies have shown that the underlying change in inferior wall infarction is transient ischaemia to the AV node and bundle of His (Sutton and Davies, 1968; Lev, Kinare, and Pick, I968). In these cases, AV block is usually reversible and of the Wenckebach type. On the contrary, as stated by Langendorf and Pick (1968), a type II Mobitz block is more frequent in anterior infarction and as a rule suggests a bilateral bundle-branch block involvement. Experiments performed by Watanabe and Dreifus (1967) are in favour of the infranodal nature of type II Mobitz block. The appearance of the latter is a bad prognostic sign in acute infarction as well as in chronic block, and constitutes an indication for intracardiac pacing (Langendorf and Pick, I968).

Post-mortem studies have revealed that in anterior infarction there is frequent necrotic 
involvement of the bundle-branches and their divisions (Sutton and Davies, 1968; Lev et al., 1968). Clinically, however, bundle-branch block and divisional block can regress (Fig. $\mathbf{I}-6)$, indicating that at times they are transient, probably ischaemic in origin (Castellanos et al., 1969).

The type II Mobitz block can also be temporary. Careful analysis of the events leading to this type of block and its frequent association with trifascicular involvement suggests that, at least in certain cases, the block might be located at the level of the divisions of the left branch (Castellanos et al., 1969).

Case 8 is atypical in that a Mobitz block occurred in a patient with an acute inferior wall infarction showing complete right bundle-branch block and block in the inferior division of the left branch. Pre-infarction tracings were not available. It is possible that the patient could have an AV block originating before bifurcation. In fact, the existence of two different areas of block, one of the bundlebranches and the other before the bifurcation had been reported in chronic block (Pick and Langendorf, 1968). However, as stated before, type II block is rare in 'pure' inferior infarction.

There is an alternative explanation for these apparently paradoxical findings. For instance, pre-existing left coronary disease might have explained the complete right block and block in the superior division of the left branch. Block in the inferior division of the left branch could have been a result of lesions in any of the two systems. If collaterals from the posterior descending artery had been supplying the anterior wall, complete right block and block in the superior and inferior division of the left branch could have been produced by a sudden occlusion of the right coronary artery, thus resulting in trifascicular block. This possibility was suggested by certain interesting electrocardiographic changes resulting from selective coronary angiography. Coskey and Magidson (1967) and Maytin, Castillo, and Castellanos (1969) noted that predictable QRS and T changes were related to injections of each vessel. After left coronary injections, there was left axis shift (presumably due to block in the superior division of the left branch) and antero-lateral ischaemia. Selective right coronary opacification produced right axis deviation (attributed to block in the inferior division of the left branch) and evidence of inferior ischaemia. The changes were called left coronary and right coronary artery response, respectively. At times, both types of response alternated after injection of a single artery. This combined response was interpreted as being due to the ischaemia in the territory normally supplied by the injected artery followed by that in the area dependent on the other vessel, now supplied by collaterals arising from the injected artery.

\section{References}

Bosco, G. A. (1936). Estudio Anatomico-topografico de la Obstruccion arterial coronaria. Artes Graficas Modernas, Buenos Aires.

Castellanos, A., Jr., Maytin, O., Arcebal, A. G., and Lemberg, L. (1969). Alternating and co-existing block in the divisions of the left branch. Diseases of the Chest, 56, 103.

Cohen, S. I., Lau, S. H., Stein, E., Young, M. W., and Damato, A. N. (1968). Variations of aberrant ventricular conduction in man; evidence of isolated and combined block within the specialized conduction system. An electrocardiographic and vectorcardiographic study. Circulation, 38, 899.

Coskey, R. L., and Magidson, O. (1967). Electrocardiographic response to selective coronary ateriography. British Heart fournal, 29, 512.

Dodge, H. T., and Grant, R. P. (1956). Mechanisms of QRS complex prolongation in man. Right ventricular conduction defects. American fournal of Medicine, 21, 534.

Evans, W., and Turnbull, H. M. (1937). The newer electrocardiogram denoting right bundle-branch block. Lancet, 2, 1127.

Grishman, A., and Scherlis, C. (1952). Spatial Vectorcardiography. Saunders, Philadelphia.

Harris, A. (1968). Etiology and treatment of acute and chronic heart block. Cardiology Digest, 3, 27.

Holzmann, M. (1953). Ungewöhnliche Ekg - Befunde bei einem Fall von av Block und wechselseitigem Schenkelblock. Cardiologia, 23, I 16.

Jouve, A., Senez, J., and Pierron, J. (1954). Diagnostic Électrocardiographique, and ed. Masson, Paris.

Katz, L. N. (1946). Electrocardiography, and ed. Lea and Febiger, Philadelphia.

Kobayashi, T. (1962). Experimental study of bundle block. Fournal of the fapanese Society of Internal Medicine, 30, $\mathrm{r}$.

Langendorf, R., and Pick, A. (1968). Editorial. Atrioventricular block, type II (Mobitz). Its nature and clinical significance. Circulation, 38, 819.

Lasser, R. P., Haft, J. I., and Friedberg, C. K. (1968). Relationship of right bundle-branch block and marked left axis deviation (with left parietal or periinfarction block) to complete heart block and syncope. Circulation, 37, 429.

Laubry, C., and Soulié, P. (1950). Les Maladies des Coronaires, 2nd ed. Masson, Paris.

Lenègre, J., and Moreau, Ph. (1963). Le bloc auriculoventriculaire chronique. Etude anatomique, clinique et histologique. Archives des Maladies $d u$ Coeur et des Vaisseaux, 56, 867.

Lepeschkin, E. (1964). The electrocardiographic diagnosis of bilateral bundle branch block in relation to heart block. Progress in Cardiovascular Disease, 6, 445.

Lev, M., Kinare, S. G., and Pick, A. (1968). The pathogenesis of atrioventricular block in coronary disease. Circulation (abstract), 38, Suppl. VI, 126.

Mahaim, I. (I931). Les Maladies Organiques du Faisceau de His-Tawara. Masson, Paris.

-, Hatt, P. Y., and Rivier, J. L. (1954). L'infarctus septal et les lésions du tissu spécifique ventriculaire. Archives des Maladies du Coeur et des Vaisseaux, 47, 465 . 
Maytin, O., Castillo, C., and Castellanos, A., Jr. (1969). The mechanisms of QRS changes produced by coronary angiography. Clinical Research, 17, 17.

Mobitz, W. (1924). Uber die unvollständige Störung der Erregungsüberleitung zwischen Vorhof und Kammer des menschlichen Herzens. Zeitschrift für die gesamte experimentelle Medizin, zugleich Fortsetzung der Zeitschrift für experimentelle Pathologie und Therapie, 41, 180 .

Pick, A., and Langendorf, R. (1968). Recent advances in the differential diagnosis of $\mathrm{A}-\mathrm{V}$ junctional arrhythmias. American Heart fournal, 76, 553.

Pryor, R., and Blount, S. G. (1966). The clinical significance of true left axis deviation. Left intraventricular blocks. American Heart fournal, 72, 391.

Rosenbaum, M. B. (1968). Types of right bundle branch block and their clinical significance. Fournal of Electrocardiology, $\mathbf{x}, 22 \mathrm{I}$.

-, Elizari, M. B., and Lazzari, J. O. (1967). Les Hemibloqueos. Paidos, Buenos Aires.
Sodi-Pallares, D., and Calder, R. M. (1956). New Bases of Electrocardiography. C. V. Mosby, St. Louis.

Sutton, R., and Davies, M. (1968). The conduction system in acute myocardial infarction complicated by heart block. Circulation, 38, 987 .

Taimont, F., Carouso, G., Mège, A., and Lenègre, J. (1952). Étude statistique des blocs de branche. 45, 927 .

Toyoshima, H., Mizuno, Y., Hattori, M., and Saruhashi, Y. (1956). A study of electrocardiographic and spatial vectorcardiographic changes in bundle branch block by means of the re-construction method. American Heart fournal, 52, 71 I.

Vastesaeger, M. M. (I946). Les troubles de la conduction intraventriculaire chez l'homme. Acta Cardiologica, Suppl. I.

Watanabe, Y., and Dreifus, L. S. (1967). Second degree atrioventricular block. Cardiovascular Research, I, 150. 